Israel Journal of Plant Sciences $\quad$ Vol.60 2012 pp.193-207
DOI: 10.1560/IJPS.60.1-2.193

\title{
Estimation of phytoplankton concentration from downwelling irradiance measurements in water
}

\author{
Peter Gege \\ Deutsches Zentrum für Luft- und Raumfahrt (DLR), Institut für Methodik der Fernerkundung, \\ 82234 Oberpfaffenhofen, Germany
}

(Received 21 July 2011; accepted in revised form 26 October 2011)

Honoring Anatoly Gitelson on the occasion of his 70th birthday

\begin{abstract}
Downwelling irradiance is so far not used directly for the determination of water constituents, mainly due to the large and unpredictable fluctuations of the underwater light field induced by the water surface. The potential of a new analytical model, which can cope with such environmental influences, was analyzed for the estimation of phytoplankton concentration using data from two German lakes. It turned out that the model is able to determine phytoplankton concentration in these lakes above a threshold between 0.4 and $0.9 \mu \mathrm{g} / \mathrm{l}$, depending on the phytoplankton class, and total pigment concentration (sum of chlorophyll-a and phaeophytin-a) with an uncertainty of $0.7 \mu \mathrm{g} / \mathrm{l}$. This new in-situ spectroscopy method is particularily of interest for shallow waters, where it is difficult to apply the usual reflectance-based algorithms due to bottom influences.
\end{abstract}

Keywords: downwelling irradiance, phytoplankton, inverse modeling, WASI

\section{INTRODUCTION}

Because it is the first link in the aquatic food chain, phytoplankton is a key parameter in ecologic sciences. Type and amount affect the water color, thus composition and concentration can be estimated using techniques that analyze spectroscopically the optical properties of water. Most quantitative spectroscopic methods are based on measurements that determine ultimately how much light is absorbed by the phytoplankton.

The absorption spectra of most phytoplankton classes are dominated by the spectral features of their main pigment, chlorophyll-a, which has absorption maxima at 443 and $674 \mathrm{~nm}$. Spectral analysis in the blue-green is more complicated than in the red because (1) spectral fine structures in the range from 400 to $570 \mathrm{~nm}$, caused by accessory pigments, change from one class to the other (Rowan, 1989; Bidigare et al., 1990), and
(2) concurring water constituents also absorb in the blue-green, and frequently much more than the phytoplankton, in particular Gelbstoff (Bowers et al., 2004). If the absorption spectra of phytoplankton and Gelbstoff are not well-known for a specific region or season, it is difficult to separate phytoplankton from Gelbstoff in the blue-green region. This is illustrated in Fig. 1. The three curves were calculated for different concentrations of phytoplankton $\left(C_{4}\right)$ and Gelbstoff $(Y)$, and for different values of the parameter $S$ which describes the shape of the Gelbstoff absorption spectrum (for details see below). The chosen values of $C_{4}, Y$, and $S$ are typical for many coastal and inland waters. The three curves are almost indistinguishable in the range from 400 to 600 $\mathrm{nm}$, i.e., analysis of spectral measurements in that range

\footnotetext{
*Author to whom correspondence should be addressed. E-mail: peter.gege@dlr.de
} 


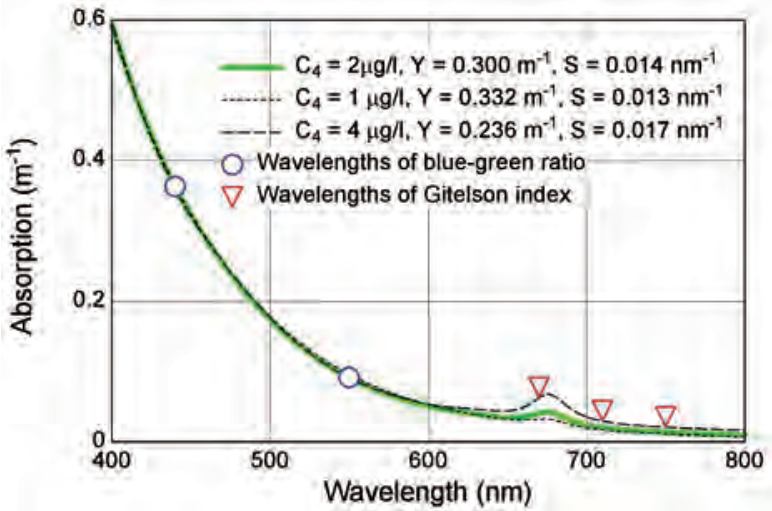

Fig. 1. Illustration of the ambiguity problem in waters with uncorrelated concentrations of phytoplankton $\left(C_{4}\right)$ and Gelbstoff $(Y)$. The plot shows the sum of phytoplankton and Gelbstoff absorption. For the chosen phytoplankton class (dinoflagellates), chlorophyll-a can be identified only by the peak at 674 $\mathrm{nm}$, while its absorption maximum at $443 \mathrm{~nm}$ is masked.

cannot determine the values of all three parameters; at least one of the parameters needs to be known.

Field spectroscopy of water constituents is commonly based either on instruments that measure in situ the absorption or attenuation coefficient of the water, like the AC-S (Zaneveld et al., 2004), or on measurements of upwelling radiation. The latter are usually normalized to the downwelling irradiance, $E_{d}$, to reduce the influence of the illumination. There exist many different approaches for data analysis of reflectance spectra (IOCCG, 2006). The most simple and computationally fastest algorithms are ratios of a few spectral bands. One of these, the very successful blue-green ratio (Gordon and Morel, 1983; O'Reilly et al., 1998), increased our knowledge of the biological activities in the oceans dramatically during the last three decades thanks to ocean color satellites. This simple two-band algorithm is taylored to the absorption spectrum of chlorophyll-a, which has a maximum in the blue (at $443 \mathrm{~nm}$ ) and a minimum in the green (around $550 \mathrm{~nm}$ ). Consequently, the reflectance ratio at these two wavelengths is highly correlated to the concentration of chlorophyll-a for water types which are dominated by chlorophyll-a or in which other constituents are strongly correlated with phytoplankton. The open oceans belong to this water type. However, for coastal, estuarine, and inland waters the blue-green ratio generally fails due to the described interference effects between phytoplankton and Gelb-stoff (Robinson, 2004). For these water types, the red and near infrared (NIR) range is better suited to estimate phytoplankton concentration (Schalles, 2006). The development of robust ratio algorithms in this region that utilize the chlorophyll-a absorption maximum at $674 \mathrm{~nm}$, was pioneered by A. Gitelson. He started with a two-band algorithm (Gitelson et al., 1985) and later transfered a three-band model, originally developed for estimating pigment contents in terrestrial vegetation (Gitelson et al., 2003, 2005), to turbid productive waters. The most robust and universally applicable algorithms use two or three wavebands around 670,710, and $750 \mathrm{~nm}$ (see the reviews of Schalles, 2006, and Gurlin et al., 2011). Gitelson and coworkers successfully applied these empirical algorithms to various turbid waters around the world to estimate phytoplankton concentration (Dall'Olmo et al., 2005; Gitelson et al., 2009; Moses et al., 2009; Gilerson et al., 2010; Yacobi et al., 2010, 2011).

The downwelling radiation is rarely used directly to derive water constituents, since the ever-changing water surface makes it highly variable in intensity (Dera and Stramski, 1993; Zaneveld et al., 2001; Hieronymi and Macke, 2012) and spectral composition (Gege and Pinnel, 2012). An analytic model has been developed that can cope with these effects (Gege, 2012). It calculates the direct and diffuse components of $E_{d}$ separately, and by treating the weights of these components as fit parameters, measurements performed at arbitrary suface conditions can be analyzed using inverse modeling. This method is optimized in this work for phytoplankton retrieval.

The method is particularily relevant for shallow waters, in which the upwelling radiation can be quite strongly affected by the bottom. Reflection at the bottom adds wavelength and angle dependent contributions to the upwelling radiation that are usually not accurately known. Moreover, the intensity of this radiance contribution from the bottom can be strongly variable since it is affected by the fluctuations of the downwelling radiation. The fluctuations don't cancel out for reflectance spectra since the upward and downward viewing instruments measure different light fields. Hence, inverse modeling of such reflectance spectra, which requires special shallow water models (Lee et al., 1999; Albert and Gege, 2006), can lead to unknown errors of the derived parameters due to the uncertainties introduced by the fluctuating water surface and the bottom properties. The new method provides an alternative to these reflectance-based algorithms.

\section{IRRADIANCE MODEL}

A depth-dependent analytical model of the downwelling irradiance $\left(E_{d}\right)$ has been developed by Gege (2012). Its basic concept and major equations are recalled briefly. The model distinguishes between the direct $\left(E_{d d}\right)$ and the diffuse $\left(E_{d s}\right)$ irradiance components and calculates total 
irradiance at depth $z$ as follows:

$$
E_{d}(\lambda, z)=f_{d d} E_{d d}(\lambda, z)+f_{d s} E_{d s}(\lambda, z) .
$$

$\lambda$ denotes wavelength. Upwelling radiation that is reflected at the water surface or scattered in the water in downward direction is neglected. The parameters $f_{d d}$ and $f_{d s}$ are the relative intensities of $E_{d d}$ and $E_{d s}$ compared to conditions with undisturbed illumination geometry. These reference conditions (with $f_{d d}=f_{d s}=1$ ) are defined by a cloudless atmosphere, unobscured view of the upper hemisphere, and by a plane water surface. $0 \leq f_{d d}<1$ corresponds to measurements when clouds, waves, or obstacles decrease the magnitude of the direct component (shadowing effect), $f_{d d}>1$ when $E_{d d}$ intensity is increased by wave focusing. Likewise, a decrease of the diffuse component is described by $0 \leq f_{d s}<1$, and an increase by $f_{d s}>1$. Note that wavelength-independent errors of $E_{d}(\lambda)$, introduced for example by erroneous sensor calibration and expressed by a multiplicative factor $(1+\varepsilon)$, correspond to $(1+\varepsilon) f_{d d}$ and $(1+\varepsilon) f_{d s}$; hence all model parameters except $f_{d d}$ and $f_{d s}$ are insensitive to such errors.

Gregg and Carder (1990) have developed a widely used analytic model for $E_{d d}$ and $E_{d s}$ just above and below the water surface. This model has been adopted to calculate $E_{d d}(\lambda, 0-)$ and $E_{d s}(\lambda, 0-)$, where the symbol 0 - indicates that the sensor is in water and just beneath the water surface. The two irradiance components have different depth dependencies, which are approximated by the following equations:

$$
\begin{aligned}
& E_{d d l}(\lambda, z)=E_{d d}(\lambda, 0-) \exp \left\{-\frac{\left[a(\lambda)+b_{b}(\lambda)\right] z}{\cos \theta_{s a t}^{\prime}}\right\} . \\
& E_{d s}(\lambda, z)=E_{d s}(\lambda, 0-) \exp \left\{-\left[a(\lambda)+b_{b}(\lambda)\right] z l_{d s}\right\} .
\end{aligned}
$$

$a(\lambda)$ is the absorption coefficient of the water layer between the surface and depth $z, b_{b}(\lambda)$ its backscattering coefficient, $\theta_{\text {sun }}^{\prime}$ the sun zenith angle in water, and $l_{d s}$ the average path length of diffuse radiation relative to sensor depth. The optical properties of the water layer are calculated as follows:

$$
\begin{gathered}
a(\lambda)=a_{W}(\lambda)+a_{p h}(\lambda)+a_{Y}(\lambda)+a_{d}(\lambda), \\
b_{b}(\lambda)=b_{b, W}(\lambda)+b_{b, X}(\lambda) .
\end{gathered}
$$

Pure water is characterized by its absorption coefficient, $a_{W}(\lambda)$, and its backscattering coefficient, $b_{b, W}(\lambda)$. Three types of absorbing water constituents are considered: phytoplankton, Gelbstoff (yellow substance; also known as colored dissolved organic matter, CDOM), and non-algal particles (detritus). These are param- eterized by their spectral absorption coefficients $a_{p h}(\lambda)$, $a_{Y}(\lambda)$, and $a_{d}(\lambda)$, respectively. Water constituents which scatter the light (suspended particles, phytoplankton cells) are represented by the spectral backscattering coefficient $b_{b, X}(\lambda)$.

\section{SOFTWARE IMPLEMENTATION}

The described model of downwelling irradiance has been implemented into the public domain software WASI (Gege, 2004a; Gege and Albert, 2006). The Water Colour Simulator WASI allows to simulate spectral measurements in aquatic environments and analyze such measurements by inverse modeling in a highly automated way. It provides a number of alternate algorithms for calculating inherent and apparent optical properties of deep and shallow waters as well as spectral radiances and irradiances, and it includes a database of optical properties of atmospheric and water constituents that can be easily modified by the user to adapt it to known optical properties from the studied area. The database provided with WASI is the result of more than 15 years of fieldwork at Lake Constance (Gege, 1994, 1998; Heege, 2000; Heege and Fischer, 2004; Miksa et al., 2004).

The pure water absorption spectrum, $a_{W}(\lambda)$, is taken from Buiteveld et al. (1994) for the range 400-786 nm, and from own unpublished measurements (which are very similar to the data of Kou et al., 1993) for the range $787-800 \mathrm{~nm}$.

Phytoplankton absorption is calculated in WASI as follows:

$$
a_{p l i}(\lambda)=\sum_{i=0}^{5} C_{i} a_{i}^{*}(\lambda)
$$

This equation allows to model mixtures of up to 6 phytoplankton classes. $C_{i}$ is the concentration of phytoplankton class number $i, a_{i}^{*}(\lambda)$ is the specific absorption coefficient of that class. The database of WASI provides 6 spectra $a_{i}^{*}(\lambda)$ which represent the phytoplankton in Lake Constance (Gege, 1998; Heege, 2000). Spectrum $\# 0$ represents a typical phytoplankton mixture in that lake, \#1 crytophyta with low concentration of the pigment phycoerythrin, \#2 crytophyta with high phycoerythrin concentration, \#3 diatoms, \#4 dinoflagellates, and $\# 5$ green algae (see Fig. 2). These spectra $a_{i}^{*}(\lambda)$ are normalized to the mass of the pigments chlorophyll-a plus phaeophytin-a per water volume $(\mu \mathrm{g} / \mathrm{l})$, thus the parameters $C_{i}$ are the concentrations of these pigments in each phytoplankton class.

Gelbstoff absorption is calculated as $a_{Y}(\lambda)=Y a_{Y} *(\lambda)$, where $a_{Y} *(\lambda)$ is the specific absorption coefficient, normalized at a reference wavelength $\lambda_{0}$, and $Y=a_{Y}\left(\lambda_{0}\right)$ 


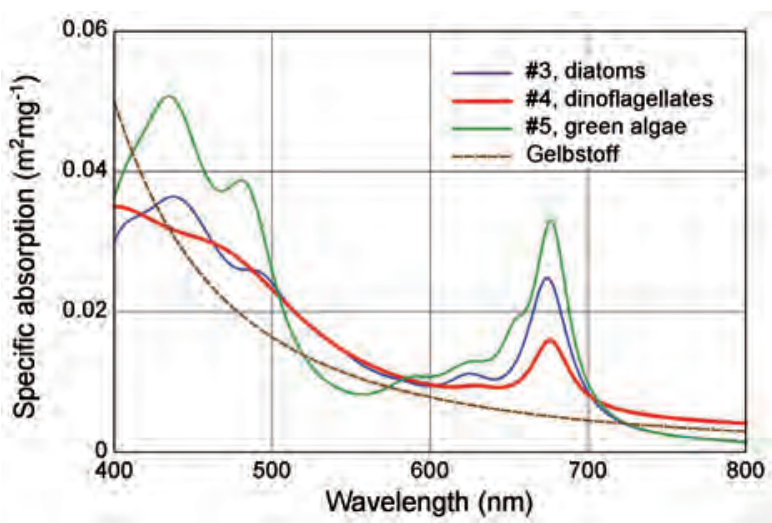

Fig. 2. Specific absorption coefficients of three phytoplankton classes (in units of $\mathrm{m}^{2} \mathrm{mg}^{-1}$ ) and of Gelbstoff (in relative units).

is the absorption coefficient at $\lambda_{0}$ in units of $\mathrm{m}^{-1}$. The spectral shape is usually approximated by an exponential function, $a_{Y}^{*}(\lambda)=\exp \left[-S\left(\lambda-\lambda_{0}\right)\right]$. The spectral slope $S$ depends on $\lambda_{0}$ (Gege, 2000) and on the chemical composition. For $\lambda_{0}=440 \mathrm{~nm}, S$ is typically in the range between $0.01 \mathrm{~nm}^{-1}$ for humic acid dominated waters and $0.02 \mathrm{~nm}^{-1}$ when fulfic acids prevail (Bricaud et al., 1981; Zepp and Schlotzhauer, 1981; Carder et al., 1989; Dekker and Peters, 1993; Kirk, 1994; Schwarz et al., 2002; Babin et al., 2003b; Laanen, 2007; Binding et al., 2008). WASI can use either the exponential approximation, or a spectrum $a_{Y} *(\lambda)$ imported from file.

WASI allows to model mixtures of two spectrally different types of suspended matter using the equation

$$
b_{b, X}(\lambda)=X \cdot b_{b, X} * \cdot b_{X}(\lambda)+C_{M i e} \cdot b_{b, M i e} * \cdot\left(\lambda / \lambda_{S}\right)^{n} \cdot(7)
$$

The first type is defined by a scattering coefficient with arbitrary wavelength dependency, $b_{X}(\lambda)$, which is imported from file. $X$ is the concentration (in units of $\mathrm{mg} / \mathrm{l}$ ) and $b_{b, X} *$ the specific backscattering coefficient (in units of $\mathrm{m}^{2} \mathrm{~g}^{-1}$ ). This type can be assigned to phytoplankton class \#0 by setting $X=C_{0}$. The second type is defined by the normalized scattering coefficient $\left(\lambda / \lambda_{S}\right)^{n}$, where the Angström exponent $n$ is related to the particle size distribution. $C_{M i e}$ is the concentration and $b_{b, M i e}$ * the specific backscattering coefficient of this type of suspended matter. In the open ocean, $n$ typically ranges from -1 for low to 0 for high (above $2 \mu \mathrm{g} / \mathrm{l}$ ) chlorophyll-a concentrations (Morel, 1988; Morel and Maritorena, 2001). In coastal waters, the backscattering coefficients are spectrally rather flat, corresponding to $n$ values around zero (Babin et al., 2003a; Chami et al., 2005). Mass-specific scattering coefficients are typically in the order of 0.5 to $1.0 \mathrm{~m}^{2} \mathrm{~g}^{-1}$ at $555 \mathrm{~nm}$ (Babin et al., 2003a), and the ratio of backscattering to total scattering ranges from about
$0.2 \%$ to $3 \%$ (Chami et al., 2005; Antoine et al., 2011), hence $b_{b, X} *$ and $b_{b, M i e} *$ are in the range from about 0.001 to $0.03 \mathrm{~m}^{2} \mathrm{~g}^{-1}$ for $\lambda_{S}$ around $555 \mathrm{~nm}$.

\section{MATERIALS AND METHODS}

\section{Dataset}

Measurements were performed in 2003 and 2004 in the German lakes Bodensee (Lake Constance) and Starnberger See at 74 stations mostly in shallow waters using a small boat (Pinnel, 2007). A dataset of $407 E_{d}$ measurements was collected using a RAMSES-ACC-VIS irradiance sensor (TriOS, Oldenburg, Germany). Each measurement consisted of 4 to 50 individual spectra that cover the range from 350 to $900 \mathrm{~nm}$ at a spectral sampling interval of $5 \mathrm{~nm}$. The $E_{d}$ sensor was lowered into the water on the sun-lit side of the boat at a distance of 2 to $3 \mathrm{~m}$ in order to avoid shadowing. More details can be found in Gege and Pinnel (2011).

At each station, water samples were collected in 0.5 $m$ depth with an opaque plastic bottle (1 1 l) in order to determine pigment concentration and the absorption spectrum of Gelbstoff. Depending on particulate matter concentration, a known water volume ( 0.5 to 2.01 ) was filtered immediately after sampling using a glass fiber filter (Schleicher \& Schuell No 6 VG4) that retains particles larger than $1 \mu \mathrm{m}$. The samples were shaded from direct sunlight during filtration and stored in cool boxes during the campaign. Laboratory analysis was performed either immediately afterwards, or within a few days after storage in a refrigerator at $-18{ }^{\circ} \mathrm{C}$. The pigments were extracted in the laboratory using hot ethanol (90\%) following the method of Nusch (1980). Particulates were separated via centrifugation. Transmission of the pigment solution was measured in $10 \mathrm{~cm}$ cuvettes at 665 and $750 \mathrm{~nm}$ using a photometer. The separation of phaeophytin-a was accomplished by a second photometric measurement at the same wavelengths, subsequent to a hydrochloric acid ( $2 \mathrm{~mol} / \mathrm{l} \mathrm{HCL})$ treatment. The concentrations of chlorophyll-a and phaeophytin-a were calculated according to the method described by Tilzer (1983).

The Gelbstoff measurements started with the same filtration procedure as for pigment determination to remove large particles. The filtered water was then filtered again using a pre-rinsed membrane filter of $0.2 \mu \mathrm{m}$ pore size (Sartorius Type 113076) and stored in small bottles of PVC or glass in a cool box until analysis. Spectral measurements were performed in the laboratory within $24 \mathrm{~h}$ of sampling using a Varian CARY-1 UV-VIS double beam spectrophotometer following the method of Gege (2004b). The transmission of each sample 
was measured twice in quartz cuvettes with 5 and 10 cm pathlengths from 190 to $900 \mathrm{~nm}$ at $1 \mathrm{~nm}$ intervals. The absorption spectrum of the sample was determined from the ratio of the two transmission spectra using the Lambert-Beer law. The Gelbstoff absorption spectrum, $a_{Y}(\lambda)$, was calculated by subtracting the same pure water absorption spectrum, $a_{w}(\lambda)$, that is also used in the model. No correction of offset or temperature was performed.

\section{Bio-optical model}

A bio-optical model is a set of equations and parameters that is used to calculate the optical properties of a water body. Since one test site was Lake Constance and no lake-specific data were available for the other site, the established bio-optical model of Lake Constance (Heege, 2000) was used. It neglects detritus absorption, $a_{d}(\lambda)$, and approximates backscattering of suspended particles by the wavelength-independent function $b_{b, X}(\lambda)=X b_{b, X}{ }^{*}$ with $b_{b, X}{ }^{*}=0.0086 \mathrm{~m}^{2} \mathrm{~g}^{-1}$. Phytoplankton is represented by the specific absorption spectra of diatoms, dinoflagellates and green algae shown in Fig. 2. For Gelbstoff absorption, both the exponential approximation $\exp \left[-S\left(\lambda-\lambda_{0}\right)\right]$ with different values of $S$, and measured spectra $a_{Y}^{*}(\lambda)$, are used.

\section{Data analysis}

Data analysis of $E_{d}(\lambda)$ measurements aims to determine the values of unknown model parameters, here $C_{3}, C_{4}$, $C_{5}, X, Y, S, f_{d d}, f_{d s}$, and $z$. This is done iteratively using WASI as follows. In the first iteration, a model spectrum $E_{d}(\lambda)$ is calculated using eq 1 for user-defined initial values of the unknown parameters (called fit parameters). This spectrum is compared with the measured one, $E_{d}^{\text {meas }}(\lambda)$, by calculating the residuum $\Sigma g_{i} \mid E_{d}^{\text {meas }}\left(\lambda_{i}\right)$ $-E_{d}\left(\lambda_{i}\right)^{2}$ as a measure of correspondence. Here, the sum was calculated for the spectral range from 400 to 800

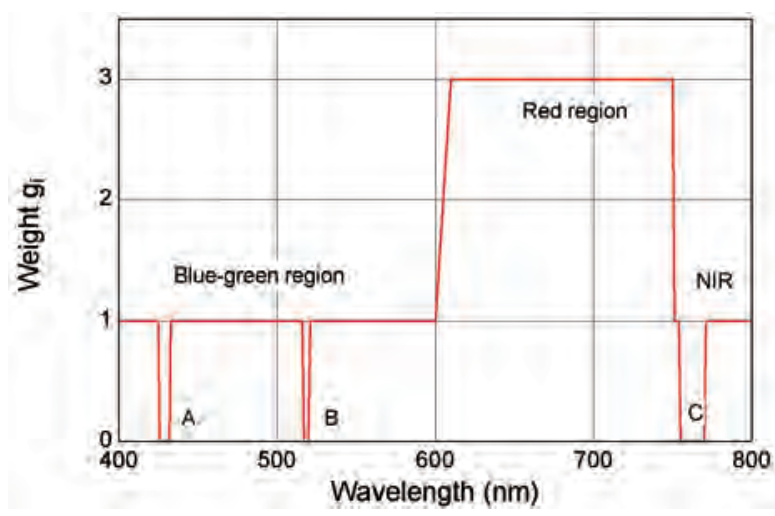

Fig. 3. Spectral weighting of correspondence between measured and calculated irradiance. $\mathrm{nm}$ in $5 \mathrm{~nm}$ steps. Then, in the further iterations, the fit parameter values are altered, resulting in altered model curves and altered residuals. The procedure is stopped when the calculated and the measured spectrum agree as well as possible, which corresponds to the minimum residuum. The values of the fit parameters of the final model curve are the fit results. This method is called inverse modeling. More details can be found in Gege and Albert (2006).

The parameters $g_{i}$ of the residuum allow wavelength-dependent weighting of the difference between measured and fit curve. $g_{i}=1$ corresponds to the classical least squares fit. The $g_{i}$ used here are shown in Fig. 3. They improve the fit results for phytoplankton concentration. The standard value of $g_{i}=1$ is used for wavelengths in the blue-green $(<600 \mathrm{~nm})$ and near infrared $(>750 \mathrm{~nm})$, except for three narrow intervals, where $g_{i}$ is set to zero since Fraunhofer lines (A: $426-432 \mathrm{~nm}$, B: 517-520 nm) and oxygen absorption (C: 755-770 nm) make $E_{d}$ measurements unreliable. The weights are increased to $g_{i}=3$ around the chlorophyll-a absorption maximum in the red. As a consequence of Fig. 1, the interval of this region is chosen as 610 to $750 \mathrm{~nm}$.

\section{RESULTS}

\section{Irradiance variability}

The effects of environmental parameters and measurement conditions on the downwelling spectral irradiance are illustrated in Fig. 4, those of water constituents in Fig. 5. All spectra were calculated using eq 1. For the reference spectrum, which is shown in blue in each row, the default values of Table 1 were used as model parameters. The default values are close to the average values of the dataset, the ranges were chosen to cover slightly more than the observed ranges. The atmospheric parameters were chosen as in chapter 6B of Gege (2012). The spectral resolution of the simulations is $1 \mathrm{~nm}$. The left columns of Figs. 4 and 5 show the series of $E_{d}(\lambda)$ spectra when the indicated parameter is changed while all other parameters remain constant at their default values. The arrows point from low to high values of the altered parameter. The right columns show the corresponding changes relative to the reference spectrum.

The comparison of Fig. 4 with Fig. 5 demonstrates that the intensity of the downwelling irradiance in water depends, for the considered parameter ranges, more on measurement and environmental conditions than on type and concentration of water constituents. Consequently, the estimation of water constituents for these conditions requires accurate modeling of the measurement and environmental conditions. 
Table 1

Model parameters used for simulation

\begin{tabular}{lcccc}
\hline Parameter & Default value & Range & Units & Description \\
\hline$z$ & 2 & $0-5$ & $\mathrm{~m}$ & Depth \\
$\theta_{\text {sun }}$ & 30 & $0-60$ & $\mathrm{deg}$ & Sun zenith angle \\
$f_{d d}$ & 1 & $0-2$ & - & Relative intensity of direct irradiance component \\
$f_{d s}$ & 1 & $0-2$ & - & Relative intensity of diffuse irradiance component \\
$C_{4}$ & 3 & $0-10$ & $\mu \mathrm{g} / 1$ & Concentration of phytoplankton class no. 4 \\
$X$ & 1 & $0-5$ & $\mathrm{mg} / 1$ & Suspended matter concentration \\
$Y$ & 0.3 & $0-1$ & $\mathrm{~m}^{-1}$ & Gelbstoff absorption at $440 \mathrm{~nm}$ \\
$S$ & 0.015 & $0.01-0.02$ & $\mathrm{~nm}^{-1}$ & Gelbstoff spectral slope \\
\hline
\end{tabular}

Changes of sensor depth not only alter very strongly the intensity of $E_{d}$ (Fig. 4a), but also introduce unique changes to the spectral shape (Fig. $4 b$ ), which is very different from all other influences. This uniqueness is due to spectral features of water absorption, particularily in the near infrared. If sensor depth is not known precisely, it can introduce significant wavelength-dependent errors to calculated $E_{d}$ spectra. However, if the spectral features in the near infrared are well resolved by the submerged instrument, sensor depth can be determined accurately from the spectral data themselves using the described model and treating $z$ as fit parameter (Grötsch and Gege, 2012).

The sun zenith angle has a large influence on the intensity of $E_{d}$ (Fig. 4c) and also affects its spectral shape (Fig. 4d). Both depend on the atmospheric conditions and on sensor depth. The relevant parameter of the former is the ratio of diffuse to direct irradiance, which depends on the sun zenith angle and on molecule and aerosol scattering in the atmosphere (Gege and Pinnel, 2011; Gege, 2011). It can be estimated using the model of Gregg and Carder (1990) or determined by a measurement of $E_{d}(\lambda)$ in air.

The most critical environmental factor is the water surface, which changes the relative intensities $f_{d d}$ and $f_{d s}$ of the direct and diffuse irradiance components in an unpredictable way. Figures $4 \mathrm{e}-\mathrm{h}$ illustrate that the induced intensity variability is very large, in particular that resulting from $f_{d d}$ changes. The effect on spectral shape is comparably low; it was on average $5 \%$ for a dataset with a standard deviation of $E_{d}$ intensity of $27 \%$ in the depth range of 0.5 to $1 \mathrm{~m}$ (Gege and Pinnel, 2011). The variability induced by the water surface is so difficult to model that some in-situ protocols recommend to make all downwelling irradiance measurements above the surface (Mueller, 2003). To the author's knowledge, the model used in this study is the only one that can handle the problem by separating $E_{d}$ into a diffuse and a direct component and by estimating $f_{d d}$ and $f_{d s}$ using inverse modeling.
Concentration changes of phytoplankton alter $E_{d}$ intensity significantly (Fig. 5a), thus it is possible in principle to determine its concentration from $E_{d}$ measurements. The changes are larger in the blue-green region than in the red. The relative changes (Fig. 5b) have the spectral shape of phytoplankton absorption (cf. Fig. 2). The shapes of these spectra differ little from one phytoplankton class to the other in the red, but significantly in the blue-green due to class-specific presence of accessory pigments. Thus exchanging the phytoplankton class in the simulations leads to relative changes of $E_{d}$ which can be spectrally distinguished in the blue-green, but not reliably in the red (Fig. 5d). Hence, the blue-green region is suitable for phytoplankton classification, but not the red region.

For the concentration range investigated here, suspended matter concentration has only slight influence on $E_{d}$ intensity (Fig. 5e). The reason is that the process of scattering re-distributes the incoming radiation, but does not change the downwelling flux much since more than $97 \%$ of the scattered photons are scattered in forward directions (Chami et al., 2005; Antoine et al., 2001). The relative changes shown in Fig. $5 f$ are wavelength-independent since the bio-optical model treats $b_{b, X}(\lambda)$ as constant. If the suspended matter is dominated by small particles, $b_{b, X}(\lambda)$ is typically proportional to $\lambda^{n}$ with $n$ in the order of -1 . In this case, the relative spectral changes are $\sim \lambda^{n}$. Since the wave focusing effect leads to spectrally very similar changes of $E_{d}$ that are approximately proportional to $\lambda^{n}$ with variable $n$ (cf. Figs. $4 \mathrm{f}$ and 4h; see also Fig. 10a in Gege and Pinnel, 2011), it is generally not possible to determine $X$ reliably from $E_{d}$ measurements. The concentration of water constituents can be estimated only for absorbing components with well-known specific absorption coefficient.

Gelbstoff concentration has a very large impact on $E_{d}$ intensity, particularily in the blue-green spectral range (Fig. 5g). The relative change of $E_{d}$ has the spectral shape of Gelbstoff absorption (cf. Fig. 2), hence changes of the line shape parameter $S$ lead to spectrally smooth changes of $E_{d}$ that are large in the blue and decrease to- 


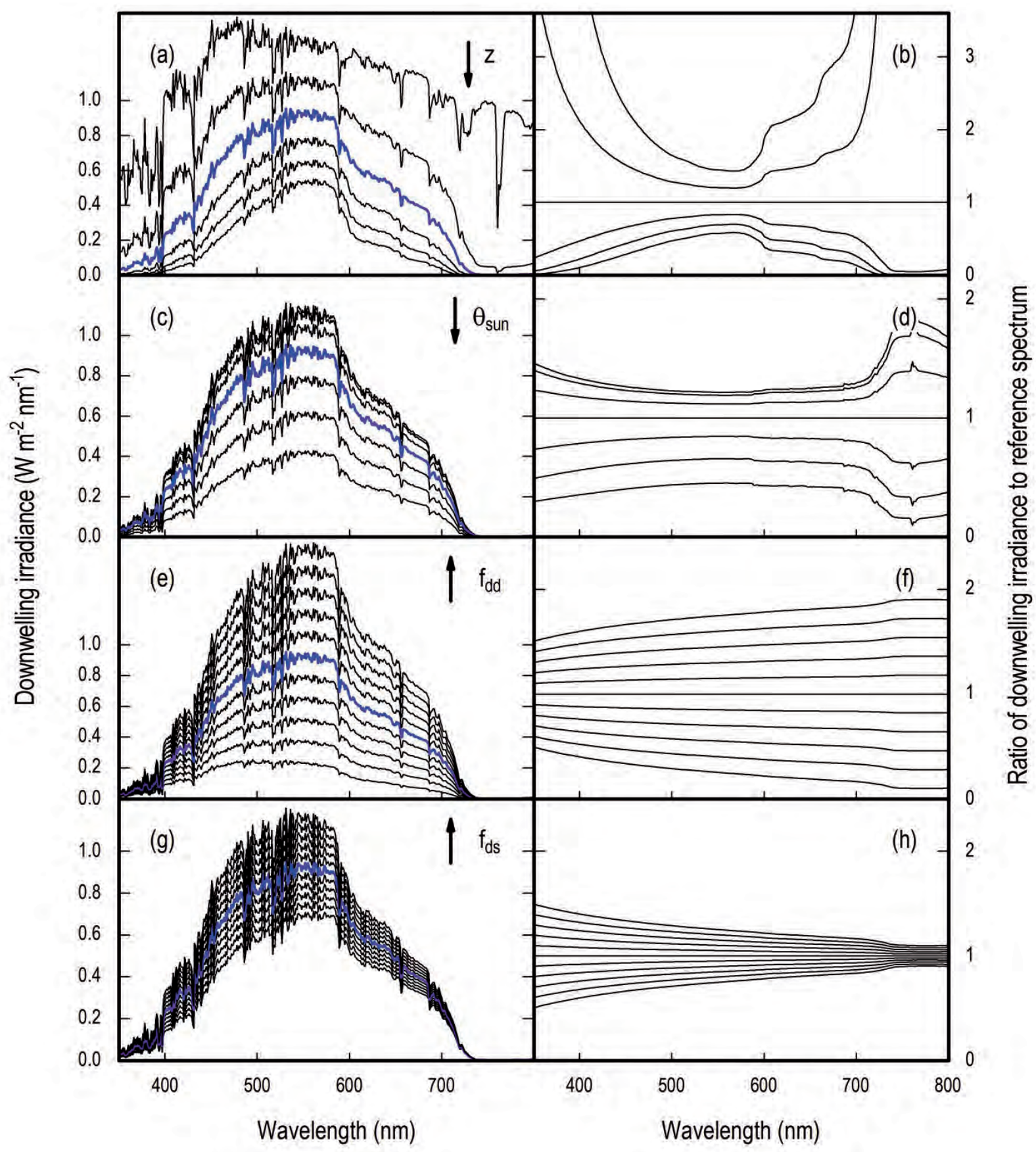

Fig. 4. Changes of downwelling irradiance with measurement and environmental conditions. Altered parameter: (a, b) Depth, 0 to $5 \mathrm{~m}$. (c, d) Sun zenith angle, 0 to $60^{\circ}$. (e, f) Relative intensity of direct irradiance component, 0 to 2 . (g, h) Relative intensity of diffuse irradiance component, 0 to 2 .

wards longer wavelengths. (Fig. 5j). These influences of Gelbstoff make the blue-green spectral region to a difficult range to estimate phytoplankton concentration. The accuracy of the results will depend on the knowledge of Gelbstoff properties.

\section{Sensitivity of fit parameters}

As illustrated by Fig. 1, it is possible that different sets of model parameters lead to very similar model curves. In such cases, the result of inverse modeling depends, 


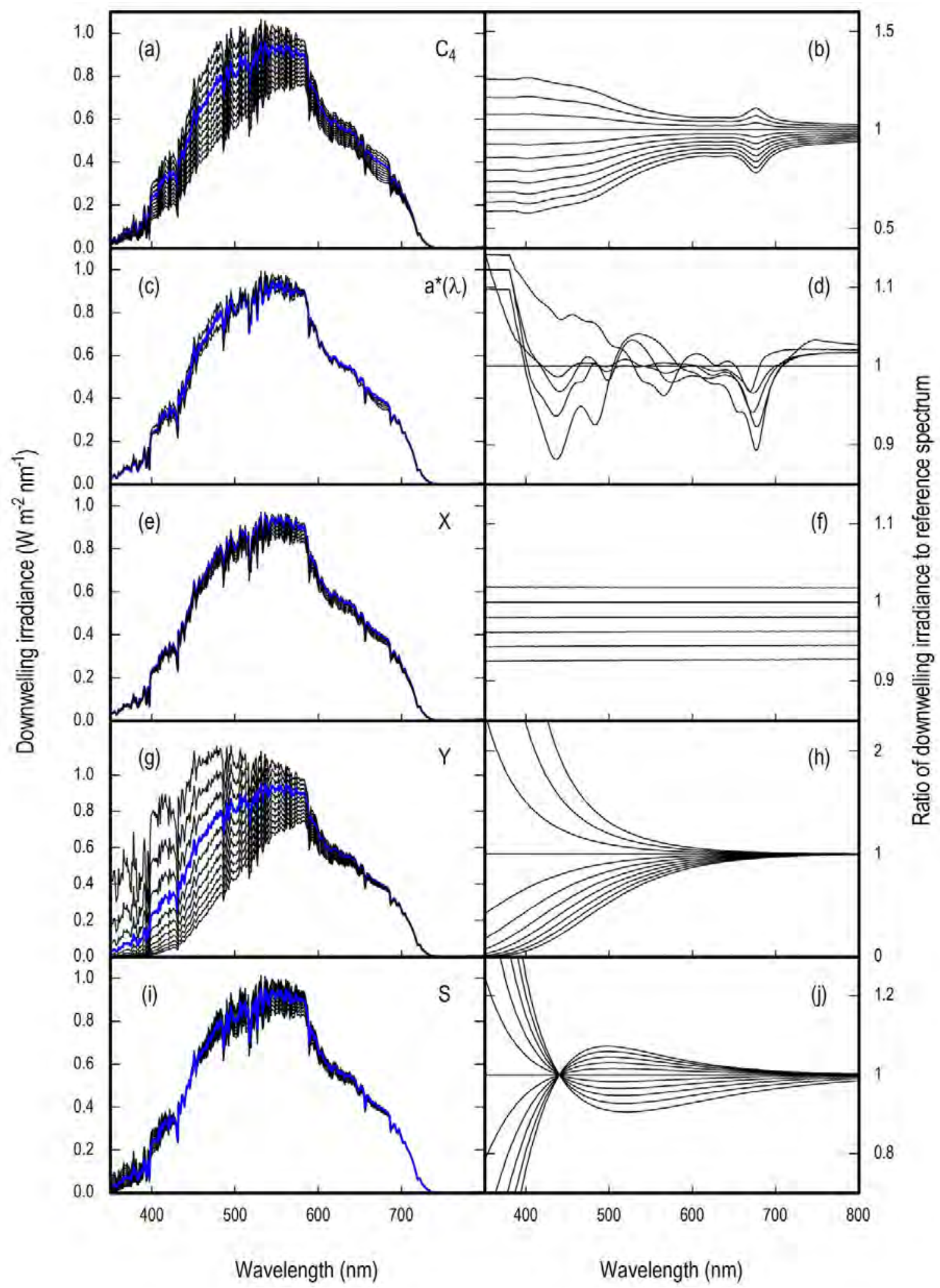

Fig. 5. Changes of downwelling irradiance with water constituents. Altered parameter: (a, b) Concentration of phytoplankton class \#4, 0 to $10 \mu \mathrm{g} / \mathrm{l}$. (c, d) Phytoplankton specific absorption coefficient, 6 classes. (e, f) Suspended matter concentration, 0 to $5 \mathrm{mg} / \mathrm{l}$. (g, h) Gelbstoff absorption at $440 \mathrm{~nm}, 0$ to $1 \mathrm{~m}^{-1}$. (i, j) Gelbstoff spectral slope, 0.01 to $0.02 \mathrm{~nm}^{-1}$. 
besides other constraints like the used bio-optical model or sensor noise, on the choice of the initial values of the fit parameters. In order to analyze this ambiguity problem for the actual dataset, inverse modeling was carried out repeatedly for selected measurements of the lakes Bodensee (BOD) and Starnberger See (STA) at altered initial values. The selection criterion was sensor depth: since a certain path length is required to measure attenuation reliably, only measurements from depths below $1.5 \mathrm{~m}$ were used. The number of selected measurements, $N$, is 35 for Bodensee, and 40 for Starnberger See. Each of these measurements consists of 4 to 50 single spectra, corresponding to a dataset of 272 spectra for Bodensee and 396 spectra for Starnberger See.

Fit parameters were $C_{3}, C_{4}, C_{5}, X, Y, S, f_{d d}, f_{d s}, z$ with initial values of $S=0.014 \mathrm{~nm}^{-1}, f_{d d}=1, f_{d s}=1$. The initial value of $z$ was determined automatically using eq. (24) in Gege (2012). The initial values of $C_{3}, C_{4}, C_{5}, X, Y$ were changed from one run to the next in order to study the influence of these initial values on the fit results. Inverse modeling was performed for each individual spectrum. Since each measurement consists of 4 to 50 spectra, the standard deviation of each fit parameter could be calculated. Table 2 summarizes the results. The lines "initial value" provide the parameter values used to calculate the first spectrum $E_{d}(\lambda)$ in the inversion procedure, "mean" summarize the average fit result of the $N$ selected measurements, and "sigma" the average standard deviation of the $N$ measurements.

In run 2 the initial value of $X$ was increased by a factor of 10 compared to run 1 . This led to an increase of the fit results for $X$ (concentration and standard deviation) by nearly the same factor, but had only minor influence on the other fit parameters except $f_{d d}$ and $f_{d s}$. Thus, the initial value choice of $X$ is not critical for the fit results of phytoplankton, Gelbstoff, and sensor depth. As discussed above (cf. Fig. 5f), changes of $X$ alter the irradiance spectrum very similar to changes of $f_{d d}$ and/or $f_{d s}$. As $f_{d d}$ and $f_{d s}$ are not known a priori under field conditions, suspended matter concentration cannot be determined.

In run 3 the initial value of $Y$ was half of that in run 1 . This reduced the fitted $Y$ concentrations by approximately $10 \%$, while the $S$ values increased. That means, the fit compensates $Y$ errors by $S$ errors, i.e., concentration and spectral slope of Gelbstoff cannot be reliably determined together from inverse modeling; one of these parameters must be known. Reason is the above shown ambiguity in the blue-green spectral region, which bears the Gelbstoff information (cf. Fig. 1). It should be noted that the upper limit of the fit values for $S$ was set to $0.025 \mathrm{~nm}^{-1}$. As this value was obtained for many single spectra as fit result, the changes of $S$ in
Table 2 are an artificial lower limit.

In run 4 the initial value of $C_{3}$ was half as in runs 1 to 3 , the inital value of $C_{4}$ was double, and the initial value of $Y$ was the same as in run 3. This ratio $C_{3}: C_{5}: C_{4}=$ $0.5: 1: 2$ is similar to the corresponding ratio of the specific absorption coefficients at $674 \mathrm{~nm}$. These changes cause an increase of the fit results for $C_{4}$, a decrease of $C_{3}$ for the data from Bodensee, and have not much influence on $C_{5}$. The Gelbstoff parameters are not significantly altered compared to run 3 . Consequently, the initial values of phytoplankton concentration have an impact on their retrieval, but all derived concentrations are consistent within the limits of a standard deviation.

The sensitivity of fit parameters to the line shape of Gelbstoff absorption was analyzed by repeating inversion for different $S$ values. To account for the result from run 3 that $S$ and $Y$ cannot be determined together, $S$ was hold constant during inversion. Further, $X=1 \mathrm{mg} / \mathrm{l}$ was set and kept constant as a consequence of run 2 . The results are summarized in Table 3.

The fit results for $C_{3}$ and $C_{5}$ are not much influenced by $S$, but very well those for $C_{4}$ : the derived $C_{4}$ values increase strongly with $S$. This different behaviour of the three phytoplankton classes is caused by differences in their specific absorption spectra in the blue-green spectral range. As illustrated in Fig. 2, classes \#3 and \#5 have distinct spectral fine structures in the range from 400 to $500 \mathrm{~nm}$ (\#3: peaks at 438 and $490 \mathrm{~nm}$, \#4: peaks at 435 and $480 \mathrm{~nm}$ ), while the spectrum of class \#4 is smooth. Since the absorption spectrum of class \#4 resembles Gelbstoff absorption more than those of the other classes, that class gets easier confused with Gelbstoff during inversion, as illustrated in Fig. 1. The magnitude of the effect is huge: doubling of $S$ induces a change of $C_{4}$ by a factor of 3 (Bodensee) to more than 10 (Starnberger See). The impact on the fit result for Gelbstoff concentration is of similar order: doubling of $S$ induces a decrease of $Y$ by a factor of 3. Consequently, the line shape of Gelbstoff absorption needs to be known very accurately to obtain reliable results for phytoplankton and Gelbstoff concentration.

\section{Spectral shape of Gelbstoff absorption}

The results of the laboratory measurements of Gelbstoff absorption are shown in Fig. 6. The y-axes are scaled logarithmically since the spectral shape follows approximately an exponential law. Each measurement (blue lines) has a convex spectral shape up to at least $600 \mathrm{~nm}$, i.e., the spectral slope $S$, which is the tangent, decreases with wavelength. The averages of all measurements are shown as yellow lines, the exponential approximation of these average spectra as brown lines. 


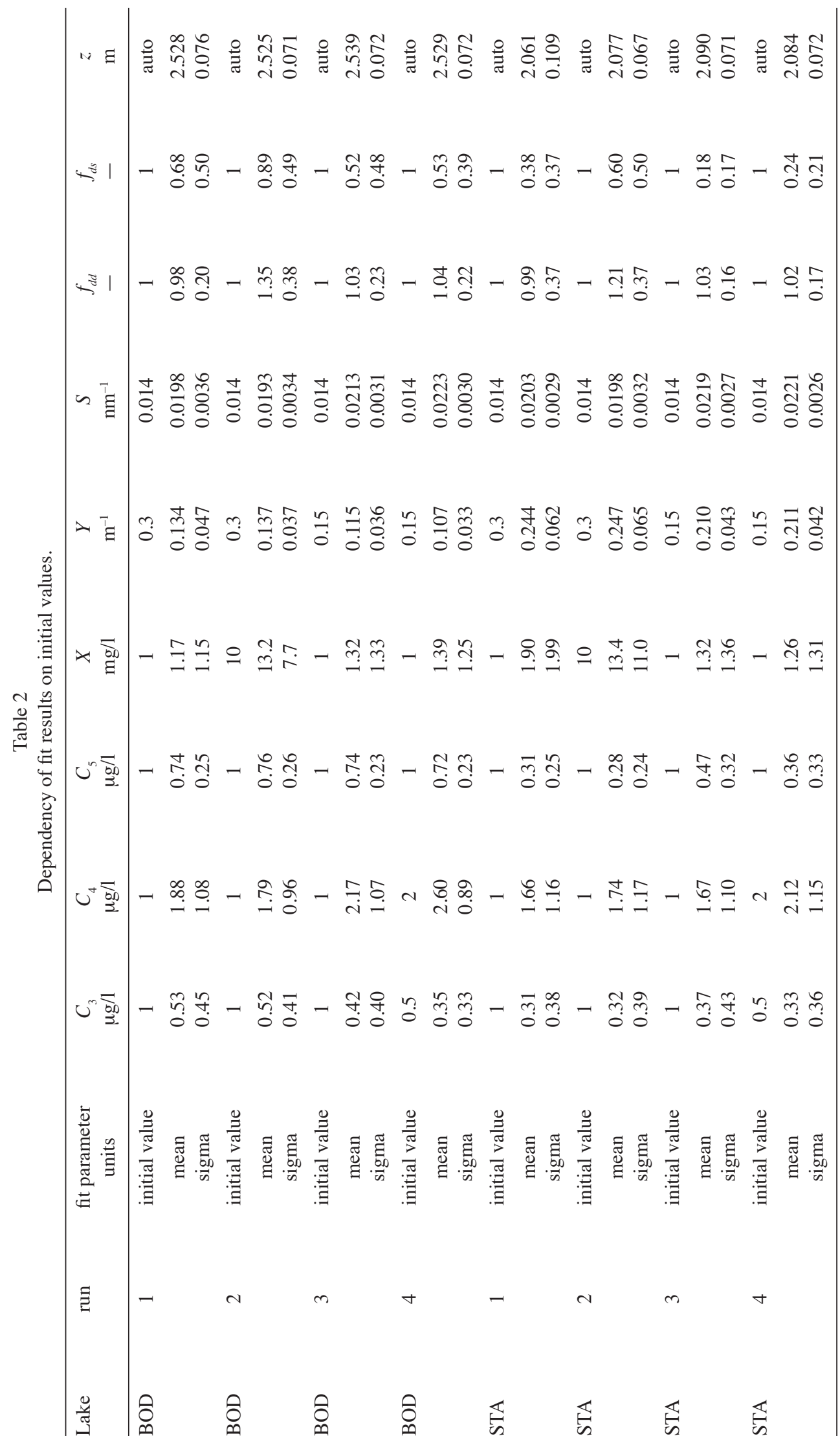


Table 3

Dependency of the fit results on the value of $S$

\begin{tabular}{|c|c|c|c|c|c|c|c|c|c|}
\hline Lake & $\begin{array}{c}\mathrm{S} \\
\mathrm{nm}^{-1}\end{array}$ & $\begin{array}{c}\text { fit parameter } \\
\text { units }\end{array}$ & $\begin{array}{c}C_{3} \\
\mu \mathrm{g} / 1\end{array}$ & $\begin{array}{c}C_{4} \\
\mu \mathrm{g} / 1\end{array}$ & $\begin{array}{c}C_{5} \\
\mu \mathrm{g} / 1\end{array}$ & $\begin{array}{c}Y \\
\mathrm{~m}^{-1}\end{array}$ & $\underline{f_{d d}}$ & $\underline{f_{d s}}$ & $\begin{array}{c}z \\
\mathrm{~m}\end{array}$ \\
\hline \multirow[t]{7}{*}{ BOD } & & initial value & 0.5 & 2 & 1 & 0.3 & 1 & 1 & auto \\
\hline & 0.010 & mean & 0.33 & 0.78 & 0.58 & 0.31 & 0.66 & 2.07 & 2.562 \\
\hline & 0.012 & mean & 0.24 & 1.46 & 0.58 & 0.24 & 0.78 & 1.42 & 2.537 \\
\hline & 0.014 & mean & 0.23 & 1.95 & 0.58 & 0.19 & 0.88 & 1.02 & 2.530 \\
\hline & 0.016 & mean & 0.23 & 2.35 & 0.58 & 0.15 & 0.94 & 0.80 & 2.526 \\
\hline & 0.018 & mean & 0.23 & 2.61 & 0.60 & 0.13 & 1.00 & 0.61 & 2.533 \\
\hline & 0.020 & mean & 0.23 & 2.69 & 0.66 & 0.11 & 1.04 & 0.47 & 2.534 \\
\hline \multirow[t]{7}{*}{ STA } & & initial value & 0.5 & 2 & 1 & 0.3 & 1 & 1 & auto \\
\hline & 0.010 & mean & 0.27 & 0.05 & 0.12 & 0.63 & 0.33 & 2.95 & 2.067 \\
\hline & 0.012 & mean & 0.26 & 0.20 & 0.13 & 0.51 & 0.55 & 1.87 & 2.066 \\
\hline & 0.014 & mean & 0.32 & 0.75 & 0.15 & 0.41 & 0.72 & 1.18 & 2.056 \\
\hline & 0.016 & mean & 0.26 & 1.43 & 0.17 & 0.33 & 0.83 & 0.77 & 2.058 \\
\hline & 0.018 & mean & 0.27 & 1.75 & 0.19 & 0.27 & 0.94 & 0.45 & 2.073 \\
\hline & 0.020 & mean & 0.26 & 2.21 & 0.20 & 0.23 & 0.99 & 0.29 & 2.070 \\
\hline
\end{tabular}
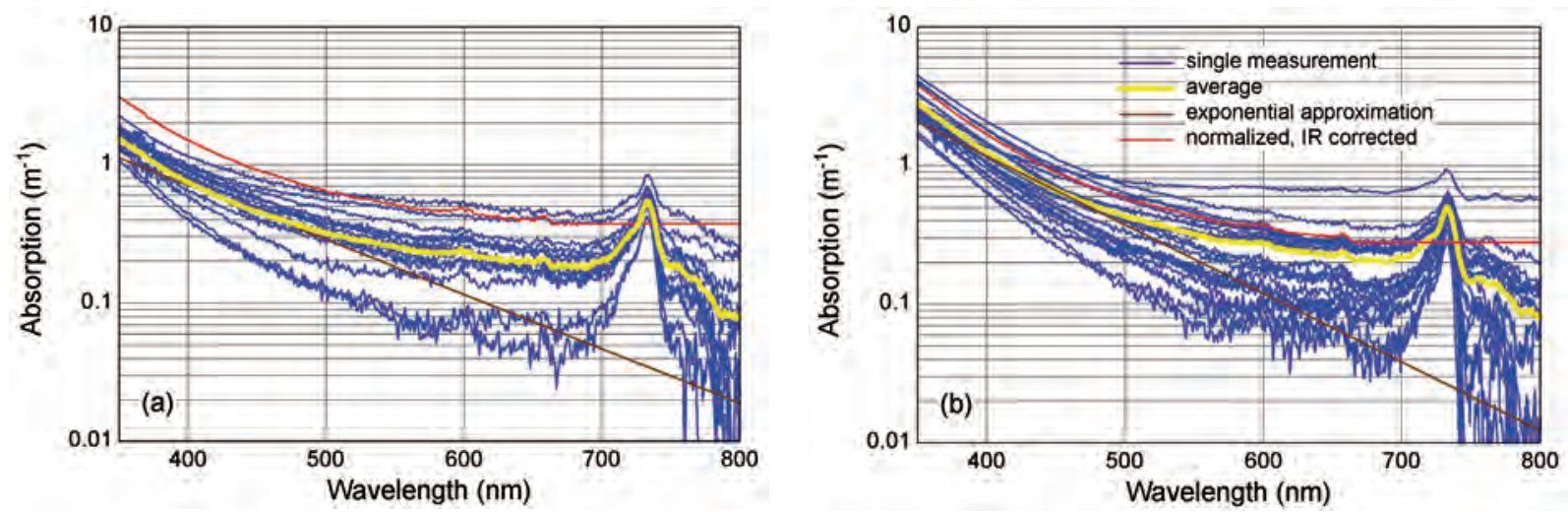

Fig. 6. Measurements of Gelbstoff absorption. (a) Bodensee, (b) Starnberger See.

At $\lambda_{0}=440 \mathrm{~nm}$, the absorption coefficient ranges from 0.22 to $0.66 \mathrm{~m}^{-1}$ (average $0.49 \mathrm{~m}^{-1}$ ) for Bodensee and from 0.31 to $1.48 \mathrm{~m}^{-1}$ (average $0.73 \mathrm{~m}^{-1}$ ) for Starnberger See. The slopes range from 0.0062 to 0.0141 $\mathrm{nm}^{-1}$ for Bodensee and from 0.0064 to $0.0214 \mathrm{~nm}^{-1}$ for Starnberger See. The averages are $0.0100 \pm 0.0025 \mathrm{~nm}^{-1}$ and $0.0126 \pm 0.0033 \mathrm{~nm}^{-1}$, respectively. These values are in the lower range of reported $S$ values $(0.01-0.02$ $\mathrm{nm}^{-1}$ ), or even lower. For Bodensee pelagial, Miksa et al. (2004) observed $Y$ values between 0.13 and $0.30 \mathrm{~m}^{-1}$ and $S$ values between 0.009 and $0.019 \mathrm{~nm}^{-1}$; for shallow water areas of Bodensee and for Starnberger See no other measurements are known.

The measured $S$ values are significantly below the fit results of Table 2, which confirms the conclusions from the previous section that $S$ cannot be determined with sufficient accuracy by inverse modeling of an $E_{d}(\lambda)$ measurement. Since the deviations of the exponential approximation from the measured line shapes lead to a general underestimation of absorption that increases with $\left|\lambda-\lambda_{0}\right|$, the two average spectra, normalized at 440 $\mathrm{nm}$ (red curves), are used below for the analysis of $E_{d}$ measurements from Bodensee and Starnberger See. Absorption is set constant above $680 \mathrm{~nm}$ where the measurements get unreliable due to temperature-induced artifacts like the peak at $733 \mathrm{~nm}$, and due to the dominance of pure water absorption compared to Gelbstoff absorption, which reduces accuracy and increases noise. It is expected that these spectra represent the spectral shape of Gelbstoff absorption better than the exponential law.

\section{Required sensor depth}

The water column above the sensor must have a certain thickness to measure reliably how much light is 

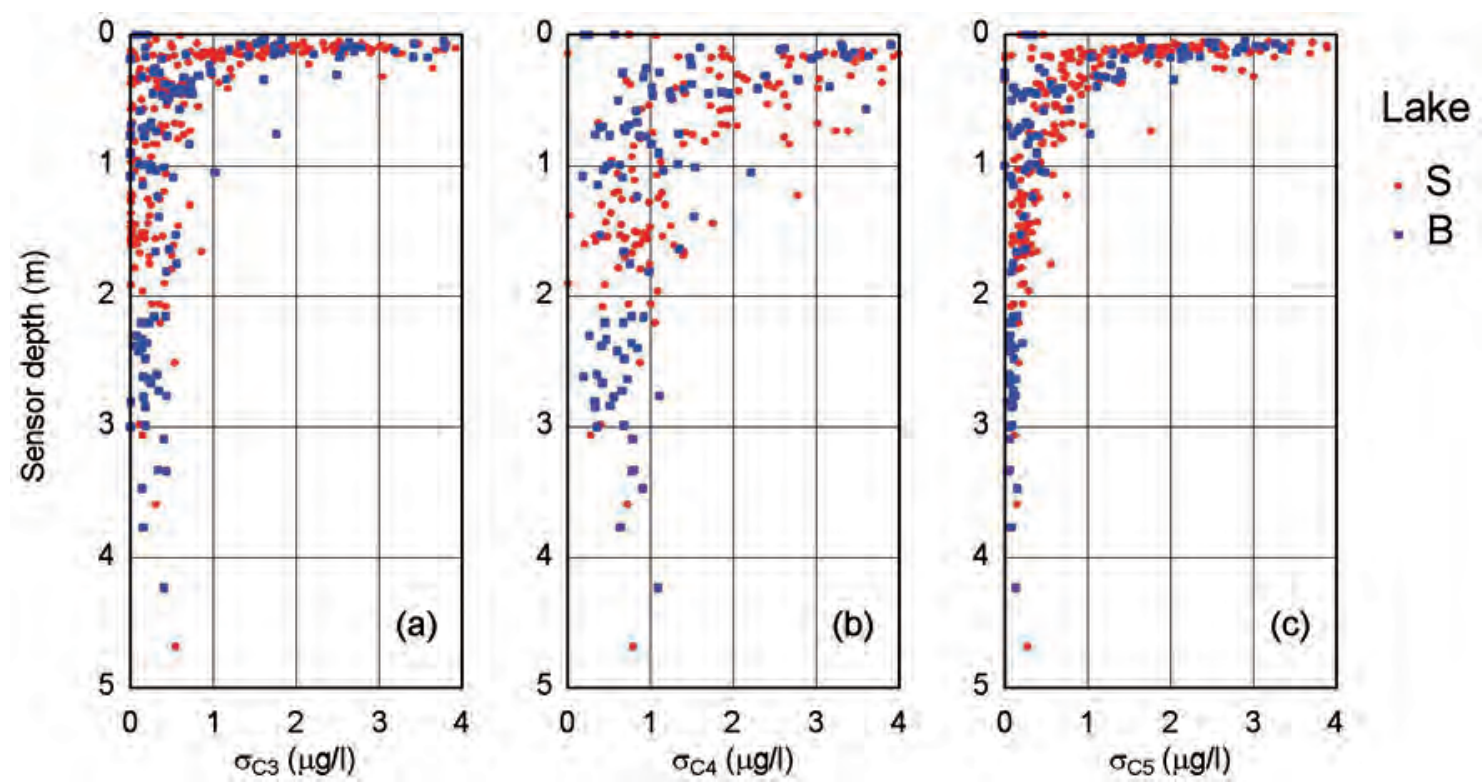

Fig. 7. Standard deviation of phytoplankton concentration as a function of sensor depth. (a) Diatoms, (b) dinoflagellates, (c) green algae.

absorbed by the phytoplankton. In order to estimate the required sensor depth, all $E_{d}$ measurements have been fitted using $C_{3}, C_{4}, C_{5}, Y, f_{d d}, f_{d s}, z$ as fit parameters. The normalized spectra shown in Fig. 6 were used to describe the line shape of Gelbstoff absorption. Since each measurement consisted of 4 to 50 single spectra, the standard deviation of each fit parameter could be calculated. Fig. 7 shows the standard deviations of $C_{3}$, $C_{4}$ and $C_{5}$ (denoted $\sigma_{\mathrm{C} 3}, \sigma_{\mathrm{C} 4}, \sigma_{\mathrm{C} 5}$ ) as a function of sensor depth.

The standard deviation can be very large close to the water surface, as expected. Values above $2 \mu \mathrm{g} / \mathrm{l}$ are observed for phytoplankton classes \#3 and \#5 at depths between 0 and $0.35 \mathrm{~m}$ and for class \#4 between 0 and $1.25 \mathrm{~m}$. The standard deviations decrease approximately exponentially with sensor depth and reach class-specific lower limits at depths between 1 and $1.5 \mathrm{~m}$. For depths below $1.5 \mathrm{~m}$, the standard deviations are on average $\sigma_{\mathrm{C} 3}$ $=0.23 \mu \mathrm{g} / \mathrm{l}, \sigma_{\mathrm{C} 4}=0.70 \mu \mathrm{g} / \mathrm{l}, \sigma_{\mathrm{C} 5}=0.15 \mu \mathrm{g} / \mathrm{l}$. For comparison, the concentration averages are $C_{3}=0.30 \mu \mathrm{g} / \mathrm{l}$, $C_{4}=1.64 \mu \mathrm{g} / 1, C_{5}=0.63 \mu \mathrm{g} / 1$. The increased standard deviations of class \#4 are caused by the variability of the spectral shape of Gelbstoff absorption, which was not accounted for during data analysis since Gelbstoff data were not available for each $E_{d}$ measurement. By defining $2 \sigma$ as the threshold for detection and quantification, the threshold concentration is $0.5 \mu \mathrm{g} / \mathrm{l}$ for phytoplankton class \#3, $1.4 \mu \mathrm{g} / \mathrm{l}$ for class \#4, and $0.3 \mu \mathrm{g} / \mathrm{l}$ for class \#5.

\section{Validation}

The described method for estimating phytoplankton concentration was validated for total pigment concentration, $C$, which is the sum of chlorophyll-a and phaeophytin-a of all phytoplankton classes. The in-situ values, $C_{\text {in situ }}$, ranged from 0.8 to $4.0 \mu \mathrm{g} / 1$ for Bodensee and from 0.7 to $1.9 \mu \mathrm{g} / \mathrm{l}$ for Starnberger See. The average concentrations are $2.5 \pm 0.9 \mu \mathrm{g} / \mathrm{l}$ and $1.4 \pm 0.3 \mu \mathrm{g} / \mathrm{l}$, respectively. By using the average specific absorption coefficient of diatoms, dinoflagellates, and green algae at $440 \mathrm{~nm}, 0.046 \mathrm{~m}^{2} \mathrm{mg}^{-1}$, the ranges of the total phytoplankton absorption coefficient are estimated as 0.04 to $0.18 \mathrm{~m}^{-1}$ (average $0.12 \mathrm{~m}^{-1}$ ) for Bodensee and 0.03 to $0.09 \mathrm{~m}^{-1}$ (average $0.06 \mathrm{~m}^{-1}$ ) for Starnberger See. Hence, phytoplankton absorbs at $440 \mathrm{~nm}$ much less light than Gelbstoff: by a factor of 6 for Bodensee, by a factor of 12 for Starnberger See on average.

A comparison of the results from inverse modeling, $C_{\text {fit }}=C_{3}+C_{4}+C_{5}$, with the corresponding in situ values is shown in Fig. 8a for all $E_{d}$ measurements at depths below $1.5 \mathrm{~m}$. As before, inverse modeling was performed using the lake-specific average Gelbstoff absorption spectra from Fig. 6, and $C_{3}, C_{4}, C_{5}, Y, f_{d d}, f_{d s}$, $z$ as fit parameters.

Even though the concentration range of the dataset is small, the fit values are highly correlated to the in-situ data, and they differ not much in their absolute values. 

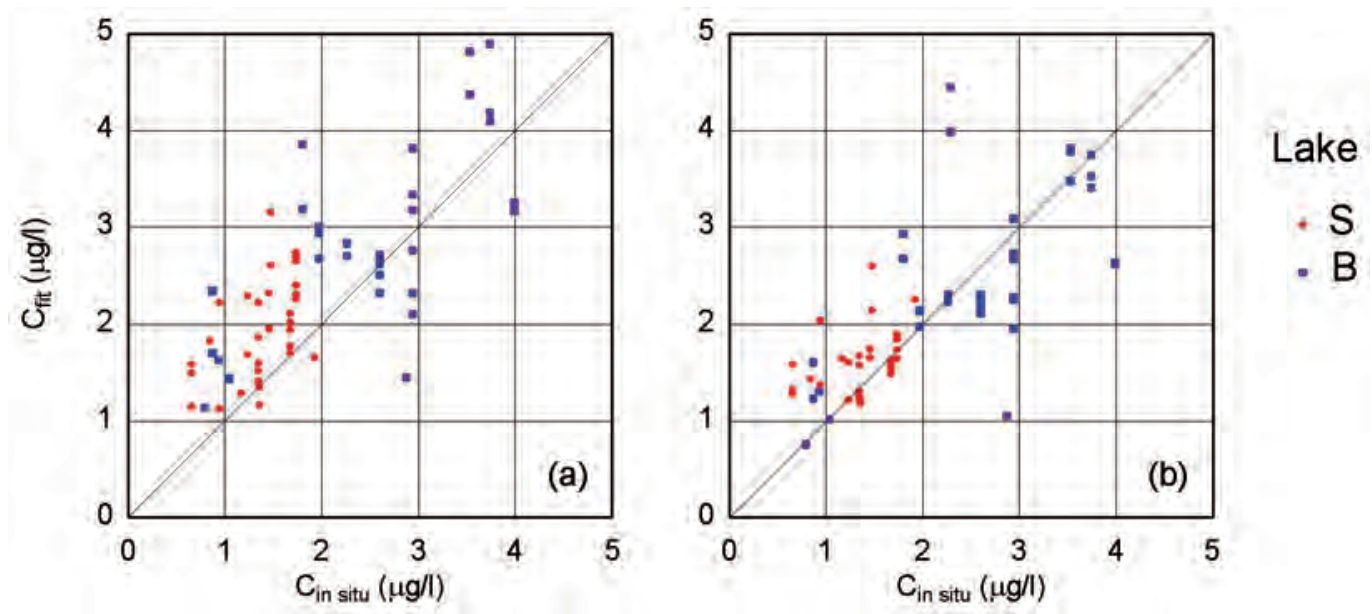

Fig. 8. Comparison of fit results for total pigment concentration (sum of chlorophyll-a and phaeophytin-a) with in-situ values. (a) Uncorrected results. (b) Using rescaled specific absorption coefficients of phytoplankton.

The correlation coefficient is $r=0.68$, the standard deviation $\sigma_{\mathrm{C}}=0.87 \mu \mathrm{g} / \mathrm{l}$, and the bias $0.52 \mu \mathrm{g} / \mathrm{l}$.

The bias indicates that the scaling of the phytoplankton specific absorption spectra may be not appropriate. These spectra were taken from the database of WASI since no actual measurements were available. It was analyzed whether the bias can be reduced and simultaneously $r$ increased by multiplying the three spectra $a_{i}^{*}(\lambda)$ with wavelength independent factors $\alpha_{i}$. The result of optimization is shown in Fig. 8b. The obtained scaling factors are $\alpha_{3}=1.0, \alpha_{4}=1.6, \alpha_{5}=0.7$. Using these, it is $r=0.74, \sigma_{\mathrm{C}}=0.66 \mu \mathrm{g} / 1$, and the bias is close to zero. The rescaled spectra $a_{i}^{*}(\lambda)$ have amplitudes of $0.025,0.026$, $0.024 \mathrm{~m}^{2} \mathrm{mg}^{-1}$ at $674 \mathrm{~nm}$ for the phytoplankton classes $\# 3$, \#4, \#5, respectively. These are much more consistent to each other than the original spectra from the WASI database, for which the corresponding amplitudes are $0.025,0.016$, and $0.033 \mathrm{~m}^{2} \mathrm{mg}^{-1}$. These improvements suggest that the rescaled spectra represent the phytoplankton for the current dataset better. Recalculating the threshold concentrations using the rescaled spectra gives $0.5 \mu \mathrm{g} / \mathrm{l}$ for class \#3, $0.9 \mu \mathrm{g} / \mathrm{l}$ for class \#4, and 0.4 $\mu \mathrm{g} / \mathrm{l}$ for class \#5.

\section{SUMMARY}

The potential of a new analytical model for downwelling irradiance in water, which can cope with the large and unpredictable fluctuations of the underwater light field, for estimating water constituents was analyzed in this study, with the focus on phytoplankton concentration. It was found that suspended matter concentration cannot be determined from downwelling irradiance measure- ments. Gelbstoff plays a critical role. Depending on the spectral shape of the specific absorption coefficient of phytoplankton, Gelbstoff can be confused with phytoplankton. In such cases the line shape of Gelbstoff absorption needs to be known accurately to obtain reliable results for phytoplankton concentration, and also to derive the concentration of Gelbstoff.

The model was applied to a dataset from two German lakes, Bodensee and Starnberger See. The concentration ranges of the absorbing water constituents were 0.7 to $4.0 \mu \mathrm{g} / \mathrm{l}$ for the phytoplankton pigments chlorophyll-a and phaeophytin-a, corresponding to absorption coefficients between 0.03 and $0.18 \mathrm{~m}^{-1}$ at $440 \mathrm{~nm}$, and 0.22 to $1.48 \mathrm{~m}^{-1}$ for Gelbstoff. For these conditions, the water column above the sensor should have a thickness of at least 1 to $1.5 \mathrm{~m}$ for accurate phytoplankton determination. The threshold concentration required to allow detection of a phytoplankton class and to estimate quantitatively its concentration depends on the class. For the classes and the dataset of this study, the thresholds (in terms of 2 standard deviations) are $0.4 \mu \mathrm{g} / \mathrm{l}$ for green algae, $0.5 \mu \mathrm{g} / \mathrm{l}$ for diatoms, and $0.9 \mu \mathrm{g} / \mathrm{l}$ for dinoflagellates. The increased uncertainty for dinoflagellates is caused by the smooth absorption spectrum of this class in the blue-green spectral region, which makes it more sensitive to errors of the lineshape of Gelbstoff absorption than the other classes. The uncertainty of total pigment concentration (sum of chlorophyll-a and phaeophytin-a) was $0.7 \mu \mathrm{g} / \mathrm{l}$. In conclusion, it was shown that the model is principally suited to estimate phytoplankton concentration from downwelling irradiance measurements. 


\section{ACKNOWLEDGMENT}

All data used for this study were measured by Nicole Pinnel. She is acknowleged for providing the data and many stimulating discussions. Two anonymous reviewers have obviously spent much time to understand all aspects of the manuscript. I am deeply greatful for their constructive and detailed comments, which were very helpful to improve completeness and clarity of the text.

\section{REFERENCES}

Albert, A., Gege, P. 2006. Inversion of irradiance and remote sensing reflectance in shallow water between 400 and 800 $\mathrm{nm}$ for calculations of water and bottom properties. Appl. Opt. 45: 2331-2343.

Antoine, D., Siegel, D.A., Kostadinov, T., Maritorena, S., Nelson, N.B., Gentili, B., Vellucci, V., Guillocheau, N. 2011. Variability in optical particle backscattering in contrasting bio-optical oceanic regimes. Limnol. Oceanogr. 56: 955-973.

Babin, M., Morel, A., Fournier-Sicre, V., Fell, F., Stramski, D. 2003a. Light scattering properties of marine particles in coastal and open ocean waters as related to the particle mass concentration. Limnol. Oceanogr. 48: 843-859.

Babin, M., Stramski, D., Ferrari, G. M., Claustre, H., Bricaud, A., Obolensky, G., Hoepffner, N. 2003b. Variations in the light absorption coefficients of phytoplankton, nonalgal particles, and dissolved organic matter in coastal waters around Europe. J. Geophys. Res., 108, C7.

Bidigare, R.R. Ondrusek, M.E. Morrow J.H., Kiefer, D.A. 1990. In vivo absorption of algal pigments. In: Spinrad, R., ed. Ocean optics X, SPIE, Bellingham, WA, pp. 290-302.

Binding, C.E., Jerome, J.H., Bukata, R.P., Booty, W.G. 2008. Spectral absorption properties of dissolved and particulate matter in Lake Erie. Remote Sens. Environ. 112: 1702-1711.

Bricaud, A., Morel, A., Prieur, L. 1981. Absorption by dissolved organic matter of the sea (yellow substance) in the UV and visible domains. Limnol. Oceanogr. 26: 43-53.

Bowers, D.G., Evans, D., Thomas, D.N., Ellis, K., le, B., Williams, P.J. 2004. Interpreting the colour of an estuary. Estuarine, Coastal Shelf Sci. 59: 13-20.

Buiteveld, H., Hakvoort, J.H.M., Donze, M. 1994. The optical properties of pure water. SPIE Vol. 2258, Ocean Optics XII, 174-183.

Carder, K.L., Harvey, G.R., Ortner, P.B. 1989. Marine humic and fulvic acids: their effects on remote sensing of ocean chlorophyll. Limnol. Oceanogr. 34: 68-81.

Chami, M., Shybanov, E.B., Churilova, T.Y., Khomenko, G.A., Lee, M.E.-G., Martynov, O.V., Berseneva, G.A., Korotaev, G.K. 2005. Optical properties of the particles in the Crimea coastal waters (Black Sea). J. Geophys. Res. 110: C11020. doi:10.1029/2005JC003008.

Dall'Olmo, G., Gitelson, A.A., Rundquist, D.C., Leavitt, B., Barrow, T., Holz, J. 2005. Assessing the potential of SeaWiFS and MODIS for estimating chlorophyll concentra- tion in turbid productive waters using red and near-infrared bands. Remote Sens. Environ. 96: 176-87.

Dekker, A.G., Peters, S.W.M. 1993. The use of the Thematic Mapper for the analysis of eutrophic lakes: A case study in The Netherlands. Int. J. Remote Sens. 14: 799-822.

Dera, J., Stramski, D. 1993. Focusing of sunlight by sea surface waves: new results from the Black Sea. Oceanologia 34: 13-25.

Gege, P. 1994. Gewässeranalyse mit passiver Fernerkundung: Ein Modell zur Interpretation optischer Spektralmessungen. Ph.D. Thesis. DLR-Forschungsbericht 1994-15, 171 pp.

Gege, P. 1998. Characterization of the phytoplankton in Lake Constance for classification by remote sensing. In: Bäuerle, E., Gaedke, U., eds. Lake Constance-Characterisation of an ecosystem in transition. Archiv für Hydrobiologie 53, pp. 179-193.

Gege, P. 2000. Gaussian model for yellow substance absorption spectra. Ocean Optics XV Conference, October 16-20, 2000, Monaco.

Gege, P. 2004a. The water color simulator WASI: an integrating software tool for analysis and simulation of optical in situ spectra. Comput. Geosci. 30: 523-532.

Gege, P. 2004b. Improved method for measuring Gelbstoff absorption spectra. Proc. Ocean Optics XVII, Fremantle, West Australia.

Gege, P., Albert, A. 2006. A tool for inverse modeling of spectral measurements in deep and shallow waters. In: Richardson, L.L., LeDrew, E.F., eds. Remote sensing of aquatic coastal ecosystem processes: science and management applications. Springer, pp. 81-109.

Gege, P. 2012. Analytic model for the direct and diffuse components of downwelling spectral irradiance in water. Applied Optics 51: 1407-1419.

Gege, P., Pinnel, N. 2011. Sources of variance of downwelling irradiance in water. Appl. Opt. 50: 2192-2203.

Gitelson, A.A., Keydan, G., Shishkin, V. 1985. Inland waters quality assessment from satellite data in visible range of the spectrum. Sov. Remote Sens. 6: 28-36.

Gitelson, A.A., Gritz, U., Merzlyak, M.N. 2003. Relationships between leaf chlorophyll content and spectral reflectance and algorithms for non-destructive chlorophyll assessment in higher plant leaves. J. Plant Physiol. 160: 271-82.

Gitelson, A.A., Viña, A., Ciganda, V., Rundquist, D.C., Arkebauer, T.J. 2005. Remote estimation of canopy chlorophyll content in crops. Geophys. Res. Lett. 32: L08403.

Gitelson, A.A., Gurlin, D., Moses, W.J., Barrow, T. 2009. A bio-optical algorithm for the remote estimation of the chlorophyll-a concentration in case 2 waters. Environ. Res. Lett. 4: 1-5.

Gilerson, A.A., Gitelson, A.A., Zhou, J., Gurlin, D., Moses, W., Ioannou, I., Ahmed, S.A. 2010. Algorithms for remote estimation of chlorophyll-a in coastal and inland waters using red and near infrared bands. Opt. Express 18: 24109-24125.

Gordon, H., Morel, A. 1983. Remote assessment of ocean color for interpretation of satellite visible imagery. A review. Springer, New York, 144 pp.

Gregg, W.W., Carder, K.L. 1990. A simple spectral solar irra- 
diance model for cloudless maritime atmospheres. Limnol. Oceanogr. 35: 1657-1675.

Grötsch, P., Gege, P. 2012. Determination of sensor depth from downwelling irradiance measurements. Proc. IGARSS, Munich, Germany, July 22-27, 2012.

Gurlin, D., Gitelson, A.A., Moses, W.J. 2011. Remote estimation of chl-a concentration in turbid productive waters - return to a simple two-band NIR-red model? Remote Sens. Environ. 115: 3479-3490.

Heege, T. 2000. Flugzeuggestützte Fernerkundung von Wasserinhaltsstoffen am Bodensee. Ph.D. thesis. DLR-Forschungsbericht 2000-40, 134 pp.

Heege, T., Fischer, J. 2004. Mapping of water constituents in Lake Constance using multispectral airborne scanner data and a physically based processing scheme Can. J. Remote Sens. 30: 77-86.

Hieronymi, M., Macke, A. 2012. On the influence of wind and waves on underwater irrradiance fluctuations. Ocean Science 8: 455-471.

IOCCG. 2006. Remote sensing of inherent optical properties: fundamentals, tests of algorithms, and applications. Lee, Z.-P., ed. Reports of the International Ocean-Colour Coordinating Group, No. 5, IOCCG, Dartmouth, Canada.

Kirk, J.T.O. 1994. Light and photosynthesis in aquatic ecosystems, 2nd ed. Cambridge University Press.

Kou, L., Labrie, D., Chylek, P. 1993. Refractive indices of water and ice in the $0.65-2.5 \mu \mathrm{m}$ spectral range. Appl. Optics 32: 3531-3540.

Laanen, M. 2007. Yellow matters - improving the remote sensing of coloured dissolved organic matter in inland freshwaters. Ph.D. thesis. Vrije Universiteit Amsterdam, 267 pp.

Lee, Z.P., Carder, K.L., Mobley, C.D., Steward, R.G., Patch, J.S. 1999. Hyperspectral remote sensing for shallow waters: 2. Deriving bottom depths and water properties by optimization. Appl. Opt. 38: 3831-3843

Miksa, S., Gege, P., Heege, T. 2004. Investigation on the capability of CHRIS-PROBA for monitoring of water constituents in Lake Constance compared to MERIS. Proc. 2nd CHRIS-PROBA workshop, Frascati, Italy, April 28-30, 2004.

Morel, A. 1988. Optical modeling of the upper ocean in relation to ist biogenous content (case I waters). J. Geophys. Res. 93: 10,749-10,768.

Morel, A., Maritorena, S. 2001. Bio-optical properties of oceanic waters: A reappraisal. J. Geophys. Res. 106: 7163-7180.

Moses, W.J., Gitelson, A.A., Berdnikov, S., Povazhnyy, V. 2009. Estimation of chlorophyll-a concentration in case II waters using MODIS and MERIS data-successes and challenges. Environ. Res. Lett. 4: 045005.

Mueller, J.L. 2003. In-water radiometric profile mMeasurements and data analysis protocols. In: Mueller, J.L., Fargion, G.S., McClain, C.R., eds. Ocean optics protocols for satellite ocean color sensor validation, Revision 4, Volume
III, NASA, pp. 7-20.

Nusch, E. 1980. Comparison of different methods for chlorophyll and phaeopigment determination. Archiv für Hydrobiologie, Special issues: Advances in Limnology, Vol. 14: 14-36.

O'Reilly, J.E., Maritorena, S., Mitchell, B.G., Siegel, D.A., Carder, K.L., Garver, S.A., Kahru, M., McClain C. 1998. Ocean color chlorophyll algorithms for SeaWiFS. J. Geophys. Res., 103(C11): 24,937-24,953.

Pinnel, N. 2007. A method for mapping submerged macrophytes in lakes using hyperspectral remote sensing. $\mathrm{PhD}$ thesis. Technical University Munich, 165 pp.

Robinson, I.S. 2004. Measuring the Oceans from Space. Springer.

Rowan, K.S. 1989. Photosynthetic pigments of algae. Cambridge University Press.

Schalles, J.F. 2006. Optical remote sensing techniques to estimate phytoplankton chlorophyll $a$ concentrations in coastal waters with varying suspended matter and CDOM concentrations. In: Richardson, L.L., LeDrew, E.F. eds. Remote Sensing of Aquatic Coastal Ecosystem Processes: Science and Management Applications. Springer, pp. 27-79.

Schwarz, J.N., Kowalczuk, P., Kaczmarek, S., Cota, G.F., Mitchell, B.G., Kahru, M., Chavez, F.P., Cunningham, A., McKee, D., Gege, P., Kishino, M., Phinney, D.A., Raine, R.. Two models for absorption by coloured dissolved organic matter (CDOM). Oceanologia 44: 209-241.

Tilzer, M. 1983. The importance of fractional light absorption by photosynthetic pigments for phytoplankton productivity in Lake Constance. Limnol. Oceanogr., 28: 833-846.

Yacobi, Y.Z., Moses, W.J., Kaganovsky, S., Sulimani, B., Leavitt, B.C., Gitelson, A.A. 2010. Chlorophyll $a$ in turbid productive waters: testing the limits of NIR-Red algorithms. Proc. 'ESA Living Planet Symposium', Bergen, Norway 28 June-2 July 2010 (ESA SP-686, December 2010)

Yacobi, Y.Z., Moses, W.J., Kaganovsky, S., Sulimani, B., Leavitt, B.C., Gitelson, A.A. 2011. NIR-red reflectancebased algorithms for chlorophyll-a estimation in mesotrophic inland and coastal waters: Lake Kinneret case study. Water research 45: 2428-2436.

Zaneveld, J.R.V., Boss, E., Barnard, A. 2001. Influence of surface waves on measured and modeled irradiance profiles. Appl. Opt. 40: 1442-1449.

Zaneveld, J.R.V., Moore, C., Barnard, A.H., Walsh, I., Twardowski, M., Chang, G.C. 2004. Correction and analysis of spectral absorption data taken with the WET Labs AC-S. Proc. Ocean Optics XVII Conference, Fremantle, Australia, October 25-29, 2004.

Zepp, R.G., Schlotzhauer, P.F. 1981. Comparison of photochemical behaviour of various humic substances in water: III. Spectroscopic properties of humic substances. Chemosphere 10: 479-486. 